\title{
Biochemistry: On bicuspid aortic valve's aortic service
}

\author{
Ari A. Mennander, MD, PhD
}

From the Tampere University Heart Hospital, Tampere, Finland.

Disclosures: Author has nothing to disclose with regard to commercial support.

Received for publication May 28, 2017; accepted for publication June 5, 2017; available ahead of print June 29, 2017.

Address for reprints: Ari A. Mennander, MD, PhD, Tampere University Heart Hospital, SDSKIR, PL 2000,

Tampere, Finland (E-mail: ari.mennander@sydansairaala.fi).

J Thorac Cardiovasc Surg 2017;154:1763

$0022-5223 / \$ 36.00$

Copyright (C) 2017 by The American Association for Thoracic Surgery

http://dx.doi.org/10.1016/j.jtcvs.2017.06.011

The purpose of studying the aorta in patients with bicuspid aortic valves (BAVs) is related to proximal aortic dilatation and the risk of dissection. If the BAV is incompetent, considerable proximal aortic dilatation requires aortic surgery. ${ }^{1}$ If the BAV is competent despite sclerosis, proximal aortic dilatation may be only relative. ${ }^{2}$ In other words, BAV per se may no longer be only considered as a disease entity including dilatation of the proximal aorta leading to dissection. This argument has been tested in investigating patients with BAV after aortic valve replacement with and without aortic surgery. ${ }^{3}$

In the current study "Elevated Oxidative Stress in the Aortic Media of Bicuspid Aortic Valve Patients" by Billaud and colleagues, ${ }^{4}$ a biochemical investigation was undertaken to show that oxidative stress is present in the proximal aorta during BAV. Ascending aortic tissue was obtained from patients with BAV and compared with aortas from patients with tricuspid aortic valves. Indicators of oxidative stress, such as superoxide anion levels, were measured using a sensitive high-pressure liquid chromatography method, and lipid peroxidation was evaluated using enzyme-linked immunosorbent assay to quantify 8 -iso-prostaglandin F $2 \alpha$. Protective indicators against oxidative stress were evaluated by investigating the enzymatic activity of superoxide dismutase and peroxidase. Indicators of oxidative stress and peroxidase activity were increased, whereas superoxide dismutase remained unchanged in BAV aortas. The most prominent difference was found in BAV aortas devoid of dilatation compared with those with dilatation or tricuspid aortic valves. A milieu of oxidative stress in the setting of BAVassociated aortopathy was suggested. ${ }^{4}$

Instead of being a trigger for ongoing aortic disease, oxidative stress also may reflect aortic wall remodeling in patients with competent $\mathrm{BAV}^{5}$; most of the patients with BAV in the study by Billaud and colleagues ${ }^{4}$ have aortic valve stenosis. ${ }^{4}$ Instead, incompetent BAV is associated with increased risk for dissection. ${ }^{2}$ Aortic media degeneration and smooth muscle cell loss may not necessarily be present during BAV. ${ }^{6}$ The total number of aortas included is reasonable, but categorizing the patients according to different phenotypes and aortic dilatation renders the groups still too small for detailed answers concerning aortic

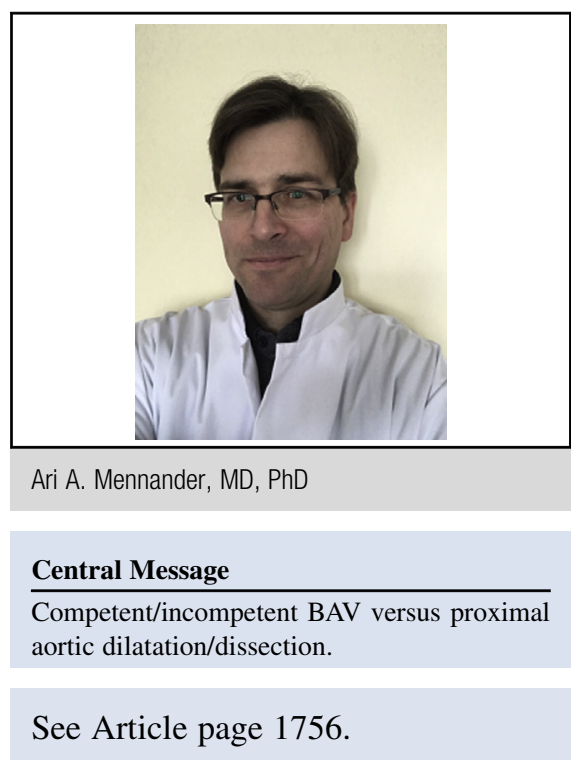

valve function. ${ }^{4}$ Molecular research has still to discover relevant genetic footprints for BAV and associated aortic disease.

The present study by Billaud and colleagues ${ }^{4}$ adds importantly to the literature of BAV and associated aortic dilatation. Because oxidative stress has a role during aortic remodeling, we should seek for the plausible clinical worth of intervening on oxidative stress in patients with aortic valve disease. Together while speculating about the significance of different phenotypes of the aortic valve, one also may ask about the consequences of a diseased aortic valve, and furthermore, what makes the functionally diseased aortic valve prone to aortic dissection.

\section{References}

1. Wang Y, Wu B, Li J, Dong L, Wang C, Shu X. Impact of aortic insufficiency on ascending aortic dilatation and adverse aortic events after isolated aortic valve replacement in patients with a bicuspid aortic valve. Ann Thorac Surg. 2016; $101: 1707-14$

2. Girdauskas E, Disha K, Borger MA, Kuntze T. Long-term prognosis of ascending aortic aneurysm after aortic valve replacement for bicuspid versus tricuspid aortic valve stenosis. J Thorac Cardiovasc Surg. 2014;147:276-82.

3. Abdulkareem N, Soppa G, Jones S, Valencia O, Smelt J, Jahangiri M. Dilatation of the remaining aorta after aortic valve or aortic root replacement in patients with bicuspid aortic valve: a 5-year follow-up. Ann Thorac Surg. 2013;96:43-9.

4. Billaud M, Phillippi JA, Kotlarczyk MP, Hill JC, Ellis BW, St Croix CM, et al. Elevated oxidative stress in the aortic media of patients with bicuspid aortic valve. J Thorac Cardiovasc Surg. 2017;154:1756-62.

5. Pasta S, Rinaudo A, Luca A, Pilato M, Scardulla C, Gleason TG, et al. Difference in hemodynamic and wall stress of ascending thoracic aortic aneurysms with bicuspid and tricuspid aortic valve. J Biomech. 2013;21:1729-38.

6. Heng E, Stone JR, Kim JB, Lee H, MacGillivray TE, Sundt TM. Comparative histology of aortic dilatation associated with bileaflet versus trileaflet aortic valves. Ann Thorac Surg. 2015;100:2095-101. 